\title{
Solar disinfection of water reduces diarrhoeal disease: an update
}

\author{
Ronán M Conroy, Michael Elmore Meegan, Tina Joyce, Kevin McGuigan, Joseph Barnes
}

\begin{abstract}
349 Maasai children younger than 6 years old were randomised by alternate household to drink water either left in plastic bottles exposed to sunlight on the roof of the house or kept indoors (control). The trial was run in Maasai by Maasai community elders. Children drinking solar disinfected water had a significantly lower risk of severe diarrhoeal disease over 8705 two weekly follow up visits; two week period prevalence was $48.8 \%$ compared with $58.1 \%$ in controls, corresponding to an attributable fraction of $16.0 \%$. While this reduction is modest, it was sustained over a year in free living children. It confirms solar disinfection as effective in vivo as a free, low technology, point of consumption method of improving water quality. The continuing use of solar disinfection by the community underlines the value of community participation in research.

(Arch Dis Child 1999;81:337-338)
\end{abstract}

Keywords: solar disinfection; diarrhoeal disease; randomised controlled trial

We previously reported a reduction in the risk of diarrhoeal disease in Maasai children aged 5 to 16 years who drank water that had been exposed to sunlight, compared with a control group who kept their drinking water indoors. ${ }^{1}$ After adjusting for confounders, the odds ratio was 0.65 (95\% confidence interval (CI) 0.50 to $0.86)$. We report on an extension of the trial to children younger than 6 years.

\section{Methods}

The methods were similar to those described in our previous report. ${ }^{1}$ We distributed plastic water bottles to the mothers of all Maasai children aged 5 or under in an area of Kajiado district, Kenya. Randomisation was by alternate household. Mothers were instructed either to place the children's drinking water on the roof of the home, exposed to sunlight, or to keep it indoors. All families were drinking water of poor quality with high levels of turbidity and bacterial contamination; all water exceeded 200 NTU (nephalometric turbidity units) and $10^{3}$ colony forming units per millilitre. All fieldwork was conducted in Maasai by a field worker who is a senior member of the community. $\mathrm{He}$ visited each home every two weeks on 26 occasions and recorded the occurrence of diarrhoea in the two week interval since the previous visit. Diarrhoea was defined using the Maasai term "enchelele" (repeated watery stools), which had to occur "more times than the fingers on one hand" (one Maasai term for "often").

Data were analysed using robust variance estimates to take account of the clustering of children within households and the repeated assessments made on each child, using the Stata procedure svylogit. ${ }^{2}$

\section{Results}

Three hundred and forty nine children in 140 households were randomised, of whom 170 $(48.7 \%)$ were girls. Mean age was 2.4 years. A total of $175(50.1 \%)$ children were in the 70 households randomised to solar disinfection. Seventy five children (33 in the solar disinfection group) were lost to follow up after the 22 nd follow up, when their families moved from the area, which was experiencing a drought. Three children died (two in the control group). There were 8705 two weekly observation periods available for analysis, of which 4323 were in the solar disinfection group.

There was a high two week period prevalence of diarrhoea: $53.5 \%$ of all two week periods having at least one episode. Two week period prevalence was $48.8 \%$ in children using solar disinfection and $58.1 \%$ in controls. Risk of diarrhoea, as indexed by two week period prevalence, was unrelated to age or sex. There was significant variation in risk of diarrhoea depending on the household's water source; there was a two week period prevalence of $42 \%$ associated with the best and $60 \%$ with the worst of the 11 water sources. Using multiple logistic regression to adjust for water source, children using solar disinfected water had an odds ratio of 0.69 (95\% CI 0.63 to 0.75 ). It should be noted that because the end point has a high prevalence, the odds ratio is not a good approximation for risk reduction, which corresponds to an attributable fraction of $16.0 \%$ in those using solar disinfection.

\section{Discussion}

Laboratory studies of solar disinfection using plastic bottles have demonstrated significant reductions in bacterial contamination even in highly turbid water. ${ }^{3}$ The results presented here confirm the utility of solar disinfection in field conditions. While a small reduction $(9.3 \%)$ in absolute risk of diarrhoea is clearly not a solution to the problem of diarrhoeal disease in children, this decrease in risk was achieved in free living Maasai families, and sustained over a period of a year. It is also notable that, as we write, over a year after completion of formal field work, almost all the households randomised to solar disinfection are continuing to use it. The acceptance by the Maasai of the 
potential benefits of solar disinfection was helped greatly by the use of Maasai workers in the conduct of the research and the dissemination of its findings. It has also focused the attention of the community on the issue of water quality, and the potential of low cost community action in improving it.

We are at present collating data from a cholera epidemic that occurred in the area, with a view to examining the possible protective effect of solar disinfection.
This work was supported by a research grant from the Royal College of Surgeons in Ireland.

1 Conroy RM, Elmore-Meegan M, Joyce T, McGuigan KG, Barnes J. Solar disinfection of drinking water and diarrhoea Barnes J. Solar disinfection of drinking water and diarrhoea
in Maasai children: a controlled field trial. Lancet in Maasai childr

2 Eltinge JL, Sribney WM. svy4: linear, logistic and probit regression for survey data. Stata Tech Bull 1996:31:26-31. 3 McGuigan KG, Joyce TM, Conroy RM, Gillespie JB, Elmore-Meegan M. Solar disinfection of drinking water contained in transparent plastic bottles: characterizing the bacterial inactivation process. F Appl Microbiol 1998;84: $1138-48$. 